\title{
Single Word Production in English: The Role of Subsyllabic Units During Phonological Encoding
}

\author{
Niels O. Schiller \\ Harvard University
}

\begin{abstract}
Five experiments investigated the role of sublexical units in English single word production. L. Ferrand, J. Segui, and G. W. Humphreys (1997) reported a priming effect that was most effective when primes and targets shared the first syllable. Experiments $1 \mathrm{~A}$ and $1 \mathrm{~B}$ failed to replicate this effect but Experiment 1B showed that subsyllabic units play a role in speech production. This role was further explored using a picture naming task in Experiment 2. Naming latencies were shortest when the segmental overlap between prime and target (the picture name) was largest, regardless of the syllable structure of the target. Experiments 3 and 4 replicated this seginental overlap effect with different sets of words as targets. Experiment 5 showed that the magnitude of the overlap effect increased with longer prime exposure duration. The implications of these results for theories of phonological encoding in speech production are discussed.
\end{abstract}

In order to speak, one retrieves words from one's mental lexicon and encodes them phonologically. In Levelt and colleagues' (Levelt, 1989, 1992, 1993, 1998; Levelt, Roelofs, \& Meyer, 1999; Levelt \& Schiller, 1998; Levelt \& Wheeldon, 1994; Roelofs, 1997a, 1997b) model of phonological encoding (see Figure 1), word form retrieval can only begin once a word form (e.g., pilot) has been accessed in the word form lexicon. Word form retrieval can be divided into metrical spellout and segmental spellout.

The work reported in this article was supported by National Institutes of Health Grant NS22201. This article benefited from discussions at the conference of the International Society of Phonetic Sciences (IPS-98, June 1998), the 1st International Conference on the Mental Lexicon (September 1998), the 10th Congress of the European Society for Cognitive Psychology (September 1998), the 39th Annual Meeting of the Psychonomic Society (November 1998), the 137th Meeting of the Acoustical Society of America (March 1999), the 2nd Linguistics Workshop on "Syllables" (March 1999), and the 14th International Congress of Phonetic Sciences (August 1999).

I thank Max Coltheart and Stephen Lupker for their insightful comments on this article. I also thank James McQueen (Max Planck Institute for Psycholinguistics, Nijmegen, the Netherlands) for his help in selecting the materials for the picture naming experiment, Inge Doehring (Max Planck Institute for Psycholinguistics) for drawing the pictures, and Ilavenil Subbiah (Harvard University) for drawing Figure 1. Thanks go to Delia Kong for running the participants in Experiment 1B. For many helpful discussions, I thank the members of the Cognitive Neuropsychology Laboratory of the Psychology Department at Harvard University and, in particular, Alfonso Caramazza, Albert Costa, Michele Miozzo, and Nina Silverberg for many useful comments on this article.

Correspondence concerning this article should be addressed to Niels O. Schiller, Cognitive Neuropsychology Laboratory, Department of Psychology, Harvard University, 33 Kirkland Street, William James Hall 918, Cambridge, Massachusetts 02138. Electronic mail may be sent to nschille@wjh.harvard.edu.
During metrical spellout, the number of syllables $(\sigma)$ of a word (or moras $[\mu]$, i.e., timing units in weight-sensitive languages) and the location of lexical stress have to be retrieved. In addition, the syllable or consonant, vowel (CV) structure of the individual syllables may also be retrieved (Costa \& Sebastián-Galles, 1998; Dell, 1988; Ferrand \& Segui, 1998; Meijer, 1994, 1996; Sevald, Dell, \& Cole, 1995; but see Roelofs \& Meyer, 1998). For example, for the word pilot, the information "two syllables, the first of which is stressed" (i.e., " $\sigma \sigma)$ has to be retrieved. Metrical spellout also includes phonological word formation, which is an important stage when words without lexical stress (e.g., prepositions, etc.) cliticize onto a word with lexical stress to form a phonological word. If we consider a sentence fragment like "the pilot of the airline," the preposition of would cliticize onto the word form pilot and together they would create a trisyllabic phonological word with stress on the initial syllable (i.e., ' $\sigma \sigma \sigma)$.

During segmental spellout, the individual segments are retrieved (e.g., $/ \mathrm{p} /, / \mathrm{a} /, / \mathrm{N} / / \partial /, / \mathrm{t} /$ ). The next step is called segment-to-frame association. During this stage, the previously retrieved segments are combined from left to right with their corresponding metrical frame respecting universal and language-specific syllabification rules (e.g., ' $\sigma\left[p_{\text {enset }}\left(a_{\text {nucleus }}\right] \sigma\left[1_{\text {onset }} a_{\text {nucleus }} t_{\text {coda }}\right]\right)$. At this point, phonological syllables are created that may serve as addresses for the retrieval of syllabic gestural scores, possibly involving access to a mental syllabary (Levelt, 1998; Levelt et al., 1999; Levelt \& Wheeldon, 1994; Schiller, Meyer, Bayen, \& Levelt, 1996). Syllabic gestural scores can be conceived of as phonetic plans specifying the relevant articulatory gestures and their relative timing for a syllable. Unlike Dell (1986, 1988), Levelt's model does not assume the representation of syllables in the word form lexicon. ${ }^{1}$ Instead,

\footnotetext{
1 This assumption is made for the following reason: In connected speech, syllabification often differs from syllabification of isolated words. Consider, for instance, the sequence almost all, which is
} 


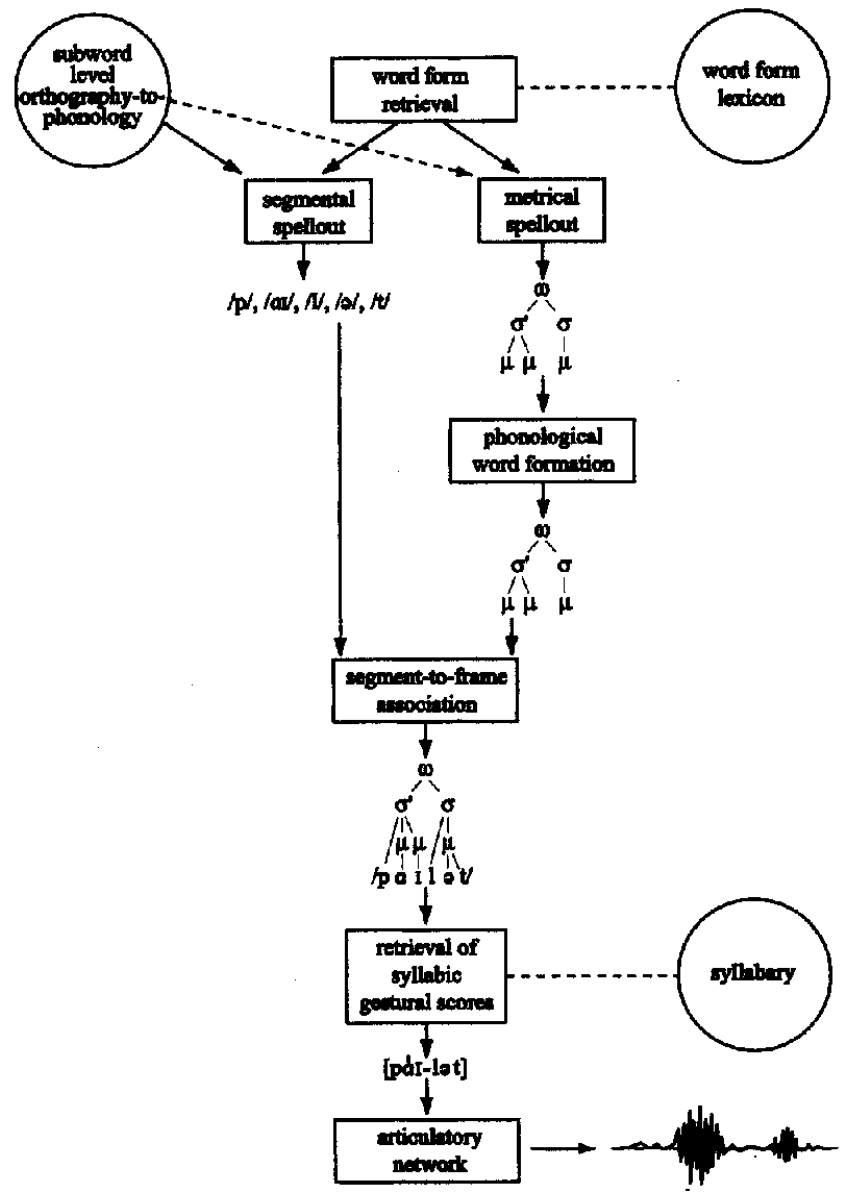

Figure 1. A theoretical model for phonological encoding in speech production. From "Do Speakers Have Access to a Mental Syllabary?"' by W. J. M. Levelt and L. Wheeldon, 1994, Cognition, 50, p. X. Copyright 1994 by Elsevier Science. Adapted with permission.

syllables are created "on the fly" when previously selected segments are associated with their corresponding metrical frames. Once syllabic gestural scores have been retrieved or generated from scratch, they are sent to the articulatory network for overt articulation of speech.

Although Levelt's model assumes the existence of syllabic units, the on-line evidence for this theoretical position in speech production is scarce. ${ }^{2}$ Recently, however, Ferrand, Segui, and Humphreys (1997) reported a syllable priming effect in English word naming, replicating earlier results from French (Ferrand, Segui, \& Grainger, 1996). For French, Ferrand et al. (1996) obtained reliable facilitation in word (Experiment 1), nonword (Experiment 2), and picture

\footnotetext{
"resyllabified" as al-mos-tall in (informal) spoken language, where the third syllable straddles a word boundary. This example shows that the syllable structure of words may vary depending on their phonological context in connected speech. It would be wasteful to have a mechanism that regularly recomputes the syllabic structure of words in an utterance (for discussion and empirical evidence see Levelt \& Wheeldon, 1994; Roelofs, 1997b).
}

naming (Experiment 4) when a letter prime shared the first syllable with a target name as compared with a condition where prime and target shared a string of segments of equal length that was either shorter or longer than the first syllable. This syllable priming effect disappeared in a visual lexicaldecision task (Experiment 3). This latter task could be performed without generating the phonological representation of the target. Therefore, Ferrand et al. (1996) argued that the syllable priming effect arises during the computation of the output phonology of the target, which is needed for overt naming. They concluded that the syllable constitutes a unit in French speech production.

In English, the production of consonant, vowel, consonant (CVC) targets (e.g., san.dal) was significantly faster when preceded by CVC primes (e.g., san\%\%\%) than when preceded by a neutral prime that consisted of percent signs only (Experiment 3). No facilitation was observed when CVC targets were preceded by $\mathrm{CV}$ primes (e.g., sa\%\%\%\%). Targets that included ambisyllabic consonants (i.e., consonants that belong to two syllables at the same time, such as the $m$ in $h a[\mathrm{~mm}] \mathrm{er}$ ) were equally facilitated by CV and CVC

${ }^{2}$ However, there is some off-line evidence, such as speech error analyses, that suggests that syllables may play a role in speech production: Segments that are involved in spontaneous speech errors usually obey the syllable position constraint, that is, onsets exchange with onsets (e.g., face spood [space food]), nuclei exchange with nuclei (e.g., cleap pik [clip peak]), etc. (examples from Fromkin, 1971). However, a quantitative analysis has shown that the vast majority of the errors occurs in onset position (e.g., of 187 consonant exchange errors in the Massachusetts Institute of Technology-Arizona corpus, $88 \%$ involved pairs of word-onset segments, leaving nucleus and coda exchanges as a marginal phenomenon in speech errors; Shattuck-Hufnagel, 1987). Therefore, the syllable position constraint may be a word-onset constraint (Shattuck-Hufnagel, 1987, 1992; see Meyer, 1992, for a critical review). Evidence from metalinguistic tasks suggests that syllables play a functional role at some level of processing in speech production (Schiller, Meyer, \& Levelt, 1997; Treiman, 1983, 1984; Treiman \& Danis, 1988). In syllable reversal experiments, participants can easily reverse the two syllables of an auditorily presented Dutch word and produce the two sylliables in the reversed order. For instance, participants would hear a CV target like ketel (/ke.təV''kettle') and produce tel-ke/tol.ke/, or they would hear a CVC target such as kaktus (/kak.tus/'cactus') and produce tus-kak (tts-kak; Schiller et al., 1997). Similar results were previously obtained in English (Treiman \& Danis, 1988). However, it is unclear at which level the syllabification takes place and what type of cognitive strategy participants use to syllabify a word. Possibly, there are (phonetic) cues to syllable boundaries in the input that are used for syllabification. Alternatively, participants may "scan" the target word in some kind of auditory buffer and determine the syllable boundaries either on the basis of orthographic information or from phonological information by subvocally rehearsing the target. By either mechanism they would ultimately be able to determine the syllable boundary and then put out the part of the word after the syllable boundary before putting out the part before the syllable boundary. Because none of these possibilities can be ultimately dismissed, it is not clear which cognitive operations occurred before participants gave their responses. Therefore, these off-line data have to be interpreted with great care when claims about speech production are made. 
primes, as compared with a neutral control condition (Experiment 4). Most importantly, significant priming effects for CV targets (e.g., re:morse) occurred in the CV priming condition but not when $\mathrm{CV}$ targets were preceded by CVC primes (Experiment 5). Experiment 1 of that study included ambisyllabic and CVC targets and showed no difference in naming latencies between the $\mathrm{CV}$ and the CVC priming condition for the ambisyllabic targets. CVC targets were produced significantly faster in the CVC priming condition than in the CV priming condition. Experiment 2 used the same targets in a lexical-decision task, again without revealing any differences between the two priming conditions. Ferrand et al. (1997) concluded that the syllable constitutes a unit of speech production in English, just as in French.

However, Experiments 2 and 4 of the Ferrand et al. (1997) study do not provide evidence for the syllable priming hypothesis because ambisyllabic targets (CV[C]; square brackets indicate ambisyllabicity) were included. Furthermore, because CVC targets were named faster when preceded by CVC primes as compared with $\mathrm{CV}$ primes (Experiment 1) or neutral primes (Experiment 3), the results of Experiments 1 and 3 are compatible not only with the syllable priming hypothesis but also with the segmental overlap hypothesis. According to this alternative hypothesis, priming effects in speech production increase when the overlap in segments between prime and target is increased. Schiller (1998) found support for the segmental overlap hypothesis in Dutch. The naming lateacies for pictures and words preceded by visually masked primes decreased when the segmental overlap between prime and target was increased. There was no relationship between the syllabic structures of prime and target, however.

Therefore, only Experiment 5 shows a clear syllable priming effect: CV targets such as remorse were named significantly faster when preceded by CV primes (e.g., re\%\%\%\%\%) but not when preceded by CVC primes (e.g., rem\%\%\% relative to the control condition. That means there is only one data point that supports the claim that syllables play a functional role in speech production in English. The present study was designed to test how reliable the syllable priming effect in English was. In order to do so, the first experiment is an exact replication of Experiment 5 of the Ferrand et al. (1997) study.

\section{Experiment 1A: Word Naming With CV Targets}

Experiment $1 \mathrm{~A}$ is an attempt to replicate Ferrand et al.'s (1997) Experiment 5. Using only CV words as targets in three different priming conditions (CV, CVC, and neutral), Ferrand et al. obtained the following results. There was no difference between the neutral and the CVC priming condition, but relative to those two priming conditions, $\mathrm{CV}$ primes yielded significant facilitation of approximately $30 \mathrm{~ms}$. Ferrand et al. interpreted this effect as a syllable priming effect. Unlike neutral and CVC primes, CV primes matched the first syllable of the target words, and therefore facilitated their naming.

Because this was the only evidence in support of the syllable priming effect, it seems worthwhile replicating the effect obtained by Ferrand et al. (1997) in order to determine how stable the syllable priming effect in English speech production is. Only CV target words with clear syllable boundaries were included. For each target word, three different types of primes were selected. CV primes shared exactly the first syllable with the target, CVC primes shared the first three segments with the target but not the first syllable, and neutral primes were composed of percent signs (\%\%).

\section{Method}

Participants. Twenty-one undergraduate students at Harvard University took part in Experiment $1 \mathrm{~A}$ in exchange for pay. All participants were native speakers of English and had normal or corrected-to-normal vision.

Procedure. The procedure was exactly the same as in the Ferrand et al. (1997) study. Participants were tested individually. They sat in front of a computer screen in a darkened room. The experimenter sat in the same room to score errors. The screen was a Macintosh color display with a refresh rate of $70 \mathrm{~Hz}$. Each trial consisted of four visual stimuli presented in rapid succession. First, a forward pattern mask consisting of nine hash marks (i.e., was presented for $500 \mathrm{~ms}$ in the center of the screen. Then the prime appeared for $30 \mathrm{~ms}$ in lowercase letters. After the presentation of the prime, a backward pattern mask was presented (i.e., \#\#\#) for $15 \mathrm{~ms}$. Then the target appeared in uppercase letters (e.g., REMORSE) and remained on the screen until a response was given. If no response was given within $2 \mathrm{~s}$, the target disappeared and after $\mathbf{5 0 0}$ ms the next trial started. Masks and prime were presented in a nonproportional font (Courier). All items appeared in the center of the screen as black characters on a white background. Each character covered approximately $0.46^{\circ}$ of visual angle from a viewing distance of approximately $80 \mathrm{~cm}$. Participants were instructed to fixate the middle of the forward pattern mask and to name the target as quickly and as accurately as possible. The presence of the prime was not mentioned. Naming latencies were measured by means of a voice key (connected to a KOSS microphone attached to an OPTIMUS MX50 headset), which was activated at the onset of target presentation. Two seconds after the voice key was triggered, the next trial started. The presentation of the trial sequences was controlled by PsychLab v1.0-103.1 (Gum \& Bub, 1988). A response was considered an error when (a) the 2-s response deadline was exceeded, (b) a speech error was included, (c) a wrong name was produced, or (d) the voice key was triggered incorrectly. Responses that included an error were excluded from the reaction time analyses.

Materials. Twenty-four CV words (taken from Ferrand et al., 1997, Experiment 5) were selected as targets (see Appendix A). All target words had clear syllable boundaries and primary stress on the second syllable. Mean frequency of occurrence per one million word forms was 37 as determined by the Francis and Kucera (1982) database.

Design. For each target word, the following three types of primes were created: (a) CV primes that shared exactly the first syllable with the target (e.g., re\%\%\%\%\%-REMORSE), (b) CVC primes that matched the first three segments of the target, but not the first syllable (e.g., rem\%\%\%\%-REMORSE), and (c) neutral primes that consisted of percent signs (e.g., \%\%\%\%\%\%\%REMORSE). Primes always matched the targets in number of characters. Prime-target pairs were rotated across the priming conditions across three blocks so that no block contained any single prime or target more than once but each block contained all three 
priming conditions. Each block was composed of 24 prime-target pairs, 8 in each condition, and then randomized individually for each participant. One third of the participants received Block 1, one third received Block 2, and one third received Block 3.

\section{Results}

Naming latencies shorter than $300 \mathrm{~ms}$ and longer than $1,000 \mathrm{~ms}$ were counted as outliers (less than $1 \%$ of the data). One participant was excluded from the analyses because of unusually high naming latencies (mean $>800 \mathrm{~ms}$ ). The mean naming latencies and error rates are summarized in Table 1. Analyses of variance (ANOVAs) were run with prime structure (CV, CVC, or neutral) and group $(1,2$, or 3$)$ as independent variables. Separate analyses were carried out with participants $\left(F_{1}\right)$ and items $\left(F_{2}\right)$ as random variables.

Error rates. There were $4 \%$ errors altogether. More errors were made in the CV priming condition (4\%) than in the neutral control (4\%) and in the CVC condition (3\%). None of the main effects nor the interaction were significant.

Reaction times. The effect of group was not significant (both $F$ values $<1$ ), but the interaction of group and prime structure was significant by items, $F_{1}(4,34)<1 ; F_{2}(4$, $42)=4.08, M S E=676.76, p<.05$. For Group 1, the CVC priming condition yielded $9 \mathrm{~ms}$ faster reaction times than the CV priming condition, but for Groups 2 and 3 , the CV priming conditions were $4 \mathrm{~ms}$ faster than the CVC priming conditions. Analyses of simple effects that were conducted for the individual groups of participants showed that the effect of prime structure did not reach significance for any one of the three groups.

The effect of prime structure was not significant, indicating the absence of a syllabic priming effect (both $F$ values $<1)$. In fact, there was almost no difference between the individual priming conditions. Naming latencies were only $1 \mathrm{~ms}$ slower in the neutral control condition $(508 \mathrm{~ms})$ than in the CV (507 ms) and the CVC priming condition (507 ms).

\section{Discussion}

The result of Experiment 1A is a clear failure to replicate the results of Experiment 5 reported by Ferrand et al. (1997). The syllable priming hypothesis predicted significantly shorter naming latencies when targets were preceded by $\mathrm{CV}$ primes as compared with CVC or neutral primes. However, using the identical materials and design, there was no effect at all, whereas Ferrand et al. reported a syllable priming effect of approximately $30 \mathrm{~ms}$.

Table 1

Mean Naming Latencies (in Milliseconds) Per Group in Experiment $1 A$

\begin{tabular}{lccc}
\hline & \multicolumn{3}{c}{ Group } \\
\cline { 2 - 4 } Prime structure & 1 & 2 & 3 \\
\hline Neutral primes & 526 & 498 & 500 \\
CV primes & 529 & 500 & 491 \\
CVC primes & 520 & 504 & 496
\end{tabular}

Note. $\mathrm{CV}=$ consonant, vowel; $\mathrm{CVC}=$ consonant, vowel, consonant.
At this point, we cannot offer an account of why we failed to replicate the syllable priming effect in English. Because the same materials and methodology used in the Ferrand et al. (1997) study were used for our study, this failure came as a surprise. However, because the result of Experiment 1A was only based on maximally 24 data points per participant, it may be argued that the statistical validity is rather low because the empirical basis was so small. Therefore, the experiment was conducted once more including a repetition of blocks to get a larger set of data points per participant.

\section{Experiment 1B: Word Naming With CV Targets}

The purpose of Experiment 1B was to investigate whether or not the failure to replicate the syllable priming effect in English (Experiment 1A) was reliable. The design of the experiment was slightly different from the previous one in order to obtain a larger data set per participant. Whereas in Experiment $1 \mathrm{~A}$ each participant named each target only once in one of three priming conditions yielding a maximum of 24 data points per participant, in Experiment 1B each participant received the same 24 targets six times, which yielded 144 items. As a result, the statistical power was increased.

\section{Method}

Participants. Twenty-one undergraduate students at Harvard University took part in Experiment $1 B$ in exchange for pay. All participants were native speakers of English and had normal or corrected-to-normal vision. None of them participated in Experiment 1A.

Procedure. The procedure was the same as in Experiment $1 \mathrm{~A}$.

Materials. The materials were identical to the materials used in Experiment 1A.

Design. The design was the same as in Experiment 1A with two exceptions. Each participant received all three blocks. The order of the blocks was counterbalanced across participants. After the completion of all blocks, the presentation of the blocks was repeated once again in the same order. Blocks were randomized individually for each participant. There was a short break between each block. Altogether, each participant received six blocks, each containing 24 trials, yielding a total of 144 trials.

\section{Results}

Naming latencies shorter than $300 \mathrm{~ms}$ and longer than $1,000 \mathrm{~ms}$ were counted as outliers (less than $1 \%$ of the data). The mean naming latencies and error rates are summarized in Table 2. ANOVAs were run with prime structure (CV, CVC, or neutral), block $(1,2$, or 3$)$, and repetition (1 or 2$)$ as independent variables.

Error rates. There were $2 \%$ errors altogether. More errors were made in the CV priming condition (3\%) than in the CVC $(2 \%)$ and in the neutral control condition $(1 \%)$. None of the main effects or interactions were significant.

Reaction times. The effect of block was only significant by participants, $F_{1}(2,40)=4.51, M S E=1,278.95, p<.05$, but not in the analysis by items, $F_{2}(2,21)<1$. Naming latencies for the first block ( $471 \mathrm{~ms}$ ) were slower than for the second and third blocks (both $459 \mathrm{~ms}$ ). The interaction of block and prime structure was not significant by participants 
Table 2

Mean Naming Latencies (in Milliseconds) and Percentage of Errors (in Parentheses) in Experiment $1 B$

\begin{tabular}{lc}
\hline & Target structure \\
\cline { 2 - 2 } Prime structure & CV words (e.g., divorce) \\
\hline Neutral primes & $466(0.8)$ \\
CV primes & $463(2.9)$ \\
CVC primes & $459(1.8)$ \\
\hline
\end{tabular}

Note. $\mathrm{CV}=$ consonant, vowel; $\mathrm{CVC}=$ consonant, vowel, consonant.

but only by items, $F_{1}(4,80)=1.25, M S E=281.30, n s$; $F_{2}(4,42)=9.38, M S E=137.33, p<.05$, and the interaction between block and repetition was only significant by participants but not by items, $F_{1}(2,40)=18.99$, $M S E=926.39, p<.05 ; F_{2}(2,21)<1$.

The effect of repetition was only significant in the item analysis but not in the analysis by participants, $F_{1}(1,20)=$ $1.61, n s ; F_{2}(1,21)=15.45, M S E=189.02, p<.05$. Items were named faster the second time $(458 \mathrm{~ms})$ than the first time $(466 \mathrm{~ms})$. However, repetition did not interact with prime structure, $F_{1}(2,40)=2.52, n s ; F_{2}(2,42)<1$.

The main effect of prime structure was significant by participants, $F_{1}(2,40)=5.73, M S E=299.68, p<.05$, and by items, $F_{2}(2,42)=3.96, M S E=137.33, p<.05$. Overall, targets were named slowest in the neutral priming condition (466 ms), faster in the CV priming condition ( $463 \mathrm{~ms}$ ), and fastest in the CVC priming condition $(459 \mathrm{~ms})$. Dunnett's tests $(p<.05)$ showed that the CVC priming condition, but not the $\mathrm{CV}$ priming condition, differed significantly from the neutral control condition. Planned comparisons revealed that the difference between the $\mathrm{CV}$ and the CVC priming condition was significant by participants but not by items, $t_{1}(20)=2.43, M S E=46.44, p<.05 ; t_{2}(23)=1.33$, ns.

\section{Discussion}

The data obtained in Experiment $1 \mathrm{~B}$ did not show a syllable priming effect. The syllable priming hypothesis predicted that CV targets would be named fastest when preceded by $\mathrm{CV}$ primes. However, in this experiment there was only a nonsignificant 3-ms facilitation in the CV priming condition compared with the neutral control condition. Furthermore, CV targets were named fastest in the CVC priming condition. In this condition, targets were named $4 \mathrm{~ms}$ faster than in the $\mathrm{CV}$ priming condition (significant by participants). That is, although all targets started with a CV syllable, they were named fastest when preceded by CVC primes. The priming effect of the CVC primes was significant when compared with the neutral control condition.

Surprisingly, Experiment 1B did not replicate Experiment 1A. Whereas in Experiment $1 \mathrm{~A}$ the naming latencies were virtually identical in all three priming conditions, in Experiment $1 \mathrm{~B}$ the main effect of prime structure was significant and there seemed to be a difference between the CV and the CVC priming condition-at least in the participant analysis.
To summarize, there are two results that seem worthwhile reporting from Experiments $1 \mathrm{~A}$ and $1 \mathrm{~B}$. First, the syllable priming effect reported by Ferrand et al. (1997) was not replicated although the same materials and method were used. Second, the overall priming effects found in Experiments $1 \mathrm{~A}(1 \mathrm{~ms})$ and $1 \mathrm{~B}(8 \mathrm{~ms})$ were much smaller than the effect reported by Ferrand et al. (approximately $30 \mathrm{~ms}$ ).

However, the pattern of results of Experiment $1 B$ seems to resemble data reported by Schiller (1998). For Dutch, he found no sign of a syllable priming effect across five word and picture naming experiments. Instead, in all experiments, priming effects increased when the overlap between prime and target was increased. This effect was called the segmental overlap effect. Because Dutch and English are very similar phonologically, especially with respect to syllable structure, on linguistic grounds it would seem plausible that the two languages would behave similarly in a syllable priming experiment. Therefore, the following four experiments further investigated the nature of the sublexical priming effect in English.

The first experiment reported below is a picture naming experiment. In the word naming task, any effects from visually presented letter primes may be due to orthographic overlap between prime and target instead of arising at the phonological output level. Picture naming does not suffer from the problem of orthographic overlap between prime and target. Furthermore, words can be named by the application of nonlexical grapheme-to-phoneme conversion (GPC) rules (Coltheart, 1978). Pictures, however, do not provide any orthographic cues. Therefore, a picture naming experiment may be crucial to investigate the nature of sublexical priming effects in English.

\section{Experiment 2: \\ Picture Naming With CV, CVC, and CV[C] Targets}

Experiment 2 tested the effect of $\mathrm{CV}$ and $\mathrm{CVC}$ primes on CV, CVC, and CV[C] targets (e.g., pi.lot, pic.nic, and pi[ll]ow). CV and CVC targets had clear syllable boundaries, whereas in the case of CV[C] targets the syllable structure was ambiguous. For the latter target category, Ferrand et al. (1997) found that both CV and CVC primes facilitated naming equally well when compared with a neutral control condition. CV targets showed facilitation only when preceded by CV primes but not by CVC primes, and for CVC targets the situation was reversed; that is, these targets were named faster only when preceded by CVC primes-as compared with a neutral control condition-but not when preceded by $\mathrm{CV}$ primes. In Dutch, however, all three target categories showed significant facilitation by $\mathrm{CV}$ primes, and even significantly more facilitation by CVC primes. Therefore, the priming effects in Dutch supported a segmental overlap hypothesis (Schiller, 1998), whereas Ferrand et al. interpreted their effect in English as being consistent with the syllable priming hypothesis.

Experiment 2 is a second attempt to resolve the discrepancy between English and Dutch. If there is a syllable priming effect in English speech production, CV targets should be named faster when preceded by $\mathrm{CV}$ primes as 
compared with neutral or CVC primes. CVC targets should show priming only when preceded by CVC primes but not when preceded by $\mathrm{CV}$ primes. Finally, both $\mathrm{CV}$ and $\mathrm{CVC}$ primes should facilitate the naming of CV[C] targets. According to the segmental overlap hypothesis, however, CVC primes should yield significantly more priming than $\mathrm{CV}$ primes for all three types of targets.

\section{Method}

Participants. Eighteen participants from the same pool as described for Experiment 1 took part in Experiment 2.

Procedure. The procedure was identical to that in Experiment 1 with the following exceptions: The forward and backward masks consisted of six hash marks (i.e., \#\#\#) instead of nine in Experiment 1, and the primes were followed by a number of percent signs such that they matched the length of the pattern masks (e.g., pi\%\%\%\%). Furthermore, pictures instead of words were used as targets. Naming latencies were measured with a voice key connected to a Radio Shack 33-3005 microphone. The next trial started $500 \mathrm{~ms}$ after the voice key was triggered.

After the completion of each experiment, participants performed post hoc tests of prime visibility to assess the amount of perceptual awareness of the primes. Participants carried out a forced-choice recognition task similar to the one used in Schiller (1998; see also Brown \& Hagoort, 1993). Syllable primes were presented under the same masking conditions as in the naming experiments, but instead of a picture or a word target the backward pattern mask was immediately followed by four different strings of characters that appeared, separated by blanks, in a row in the center of the screen. One of these four strings was identical to the syllable prime; the others were foils. Foils were legal syllables of English, either consisting of two letters (CV) or of three letters (CVC). A single trial consisted of two 2-letter strings and two 3-letter strings. Position of the target was counterbalanced across trials. The results of the visibility tests are summarized in Table 3 . The fact that participants performed practically at chance level in the tests of prime visibility (except for Experiment 5) reflects the participants' subjective reports that they were generally unaware of the presence of the primes. ${ }^{3}$

Materials. Altogether, there were 48 black-on-white line drawings of common objects, 16 for each of the three target categories (i.e., CV, CVC, and CV[C]; see Appendix B). The target pictures were selected on the basis of the results obtained in two pretests. The first pretest was carried out to determine the dominant naming responses to a set of pictures. Twelve participants viewed printed line drawings of 94 objects and were asked to write down their names. The second pretest was designed to determine the mean response latencies for those pictures that were most consistently named in the first pretest. For this second pretest, another 12 participants first leamed the names of 77 objects and were then

Table 3

Percentage of Correct Responses (PC) With Standard Errors in the Prime Visibility Tests Used in Experiments 2-5

\begin{tabular}{ccc}
\hline Experiment & PC (\%) & \multicolumn{1}{c}{$S E$} \\
\hline 2 & 27 & 6.84 \\
3 & 28 & 23.68 \\
4 & 29 & 31.49 \\
5 & 42 & 99.24 \\
\hline
\end{tabular}

asked to name the pictures as quickly and as accurately as possible on a computer screen. Response latencies were measured with a voice key. Incorrect naming responses were excluded from the reaction time analyses. As can be seen in Table 4 , the 48 picture stimuli that were selected on the basis of the two pretests are matched as closely as possible with respect to mean frequency of occurrence, mean proportion of correct naming responses in spontaneous naming, and mean naming latencies.

All selected picture names corresponded to monomorphemic bisyllabic English nouns. Word length was between four and six letters. Mean word length in letters was 4.8 for the CV targets and 5.9 for both CVC and CV[C] targets. All targets had lexical stress on the first syllable. The mean frequency of occurrence per one million word forms (COBUILD corpus) was 29.4 for the $\mathrm{CV}$ targets, 22.8 for the CVC targets, and 9.5 for the CV[C] targets as determined by the CELEX lexical database for English (Baayen, Piepenbrock, \& Gulikers, 1995; Burnage, 1990).

There were two types of related primes corresponding either to the first two letters (CV primes) or to the first three letters of a target's name (CVC primes). In addition, there was a neutral control prime consisting of nonlinguistic characters. For example, for the CVC target pic.nic the primes were pi\%\%\%\% (CV prime), pic\%\%\% (CVC prime), and \%\&\$\%\% (neutral prime).

Design. Experiment 2 had a within-participants design. Participants received one learning, two practice, and three test blocks. In the learning block, participants saw each picture once on the computer screen to learn the appropriate picture names. Each picture appeared on the screen, and after $2 \mathrm{~s}$ the appropriate name was added below the picture. Both remained in view for another 3 s. Participants were asked to learn the appropriate name for each picture. Following this learning phase, participants received two practice and three test blocks. In a practice block, each target was presented once preceded by a fixation point. In the rare event that participants did not produce the appropriate name for a given picture in a practice block, they were corrected by the experimenter after that practice block. In a test block, each target appeared once in each of the three priming conditions. Items were randomized individually for each participant and block with the following constraints: Identical targets were separated by at least 30 trials, and the same target type and prime type could not be repeated more than once consecutively. There was a short break between each block.

\section{Results}

Naming latencies shorter than $350 \mathrm{~ms}$ and longer than $1,500 \mathrm{~ms}$ were counted as outliers (less than $1 \%$ of the data). The mean naming latencies and error rates are summarized in Table 5. ANOVAs were run with target structure (CV, CVC, or CV[C]), prime structure (CV, CVC, or neutral), and block $(1,2$, or 3$)$ as independent variables. Separate analyses were carried out with participants $\left(F_{1}\right)$ and items $\left(F_{2}\right)$ as random variables.

Error rates. There were $2 \%$ errors altogether. There was a significant interaction of target and prime structure, $F_{1}(4$,

\footnotetext{
${ }^{3}$ In a post hoc analysis, only data from those 12 participants who had less than $50 \%$ correct responses in the prime visibility test for Experiment 5 were analyzed again. However, the results were very similar to the analysis of the whole set of participants, and the effects were the same (means: neutral prime $=451 \mathrm{~ms}, \mathrm{CV}$ prime $=439 \mathrm{~ms}, \mathrm{CVC}$ prime $=434 \mathrm{~ms}$ ). This shows that the segmental overlap effect is not contingent on prime visibility.
} 
Table 4

Mean Frequency of Occurrence, Mean Proportion of Correct Naming Responses, and Mean Naming Latencies of the Selected Picture Stimuli Used in Experiment 2

\begin{tabular}{lccc}
\hline $\begin{array}{c}\text { Target } \\
\text { structure }\end{array}$ & $\begin{array}{c}\text { Mean frequency of } \\
\text { occurrence per one million } \\
\text { word forms (CELEX) }\end{array}$ & $\begin{array}{c}\text { Mean proportion of } \\
\text { correct responses } \\
\text { (Pretest 1; \%) }\end{array}$ & $\begin{array}{c}\text { Mean naming } \\
\text { latencies } \\
\text { (Pretest 2; ms) }\end{array}$ \\
\hline CV targets & 29.4 & 61 & 764 \\
CVC targets & 22.8 & 85 & 720 \\
CV[C] targets & 9.5 & 95 & 704 \\
\hline
\end{tabular}

Note. $\mathrm{CV}=$ consonant, vowel; $\mathrm{CVC}=$ consonant, vowel, consonant; $\mathrm{CV}[\mathrm{C}]=$ consonant, vowel, ambisyllabic consonant.

68) $=2.95, M S E=0.23, p=.026 ; F_{2}(2,90)=2.61$, $M S E=0.30, p=.041$. Analyses of the simple effects revealed that this interaction was due to an effect of prime structure within CVC target category, which was marginally significant by participants and significant by items, $F_{1}(2$, $34)=3.18, M S E=0.30, p=.054 ; F_{2}(2,90)=3.63$, $M S E=0.30, p=.031$. More errors were made in the CV priming condition $(2 \%)$ than in the CVC $(1 \%)$ and in the neutral control condition $(0.8 \%)$. None of the other effects or interactions was significant.

Reaction times. Neither the main effect of block nor any of the interactions involving this variable were significant. Therefore, the data were collapsed across blocks for the subsequent analyses.

Target structure interacted with prime structure, $F_{1}(4$, $68)=4.99, M S E=182.59, p=.001 ; F_{2}(4,90)=5.07$, $M S E=160.85, p=.001$. This interaction reflects the fact that the primes had different effects in the individual target categories (see Table 5). However, there was no sign of a syllable priming effect.

The main effect of prime structure was significant, $F_{1}(2$, $34)=15.18, M S E=312.31, p<.001 ; F_{2}(2,90)=27.89$, $M S E=160.85, p<.001$. Overall, target names were produced fastest when preceded by a CVC prime $(596 \mathrm{~ms})$, slower when preceded by a CV prime $(609 \mathrm{~ms})$, and slowest when preceded by a neutral prime $(615 \mathrm{~ms})$. Because of the interaction with target structure, the effect of prime structure was tested in each individual target category (analyses of simple effects). It turned out that the effect of prime structure was significant for $C V, F_{1}(2,34)=5.11, M S E=215.19$, $p=.011 ; F_{2}(2,90)=7.27, M S E=160.85, p=.001$, and CVC items, $F_{1}(2,34)=19.37, M S E=247.54, p<.001$;
$F_{2}(2,90)=26.87, M S E=160.85, p<.001$. For CV[C] items the effect of prime structure was marginally significant by participants and significant by items, $F_{1}(2,34)=3.12$, $M S E=214.77, p=.057 ; F_{2}(2,90)=3.88, M S E=160.85$, $p=.024$. Dunnett's tests $(p<.05)$ showed that the CV priming condition differed significantly from the neutral control condition for the CVC targets and that the CVC priming condition differed significantly from the neutral control condition for all target structures. Planned comparisons revealed that the differences between the $\mathrm{CV}$ and the CVC priming condition were significant for all target structures-for the CV items: $t_{1}(17)=3.03, M S E=215.19$, $p<.05 ; t_{2}(47)=3.62, M S E=160.85, p<.05$; for the CVC items: $t_{1}(17)=2.49, M S E=247.54, p<.05 ; t_{2}(47)=2.92$, $M S E=160.85, p<.05$; for the CV[C] items: $t_{1}(17)=2.16$, $M S E=214.77, p<.05 ; t_{2}(47)=2.38, M S E=160.85$, $p<.05$.

\section{Discussion}

The data show that there was a sublexical priming effect. However, this was not caused by a syllable priming effect. Although there was an interaction of target and prime structure, this was not due to syllabic overlap. For all target structures, CVC primes yielded significantly more facilitation than did CV primes. This is support for the segmental overlap hypothesis. However, when compared with the neutral control condition, CV primes yielded significant facilitation only in the case of CVC targets. For the CV and $\mathrm{CV}[\mathrm{C}]$ targets, CV primes did not show any effect. Therefore, although the overall pattern of results clearly contradicted the syllable priming hypothesis, it was not fully in

Table 5

Mean Naming Latencies (in Milliseconds) and Percentage of Errors (in Parentheses) in Experiment 2

\begin{tabular}{llccc}
\hline & \multicolumn{4}{c}{ Target structure } \\
\cline { 2 - 5 } $\begin{array}{c}\text { Prime } \\
\text { structure }\end{array}$ & $\begin{array}{l}\text { CV pictures } \\
\text { (e.g., pilot) }\end{array}$ & $\begin{array}{c}\text { CVC pictures } \\
\text { (e.g., picnic) }\end{array}$ & $\begin{array}{c}\text { CV[C] pictures } \\
\text { (e.g., pillow) }\end{array}$ & $M$ \\
\hline Neutral primes & $621(2.1)$ & $616(0.8)$ & $608(2.0)$ & 615 \\
CV primes & $624(1.4)$ & $596(2.4)$ & $608(2.0)$ & 609 \\
CVC primes & $609(1.4)$ & $583(1.3)$ & $597(1.4)$ & 596 \\
\hline
\end{tabular}

Note. $\mathrm{CV}=$ consonant, vowel; $\mathrm{CVC}=$ consonant, vowel, consonant; $\mathrm{CV}[\mathrm{C}]=$ consonant, vowel, ambisyllabic consonant. 
Table 6

Mean Naming Latencies (in Milliseconds) and Percentage of Errors (in Parentheses) in Experiment 3

\begin{tabular}{lcccc}
\hline \multicolumn{4}{c}{ Target structure } \\
\cline { 2 - 5 } Prime & $\begin{array}{c}\text { CV words } \\
\text { structure }\end{array}$ & $\begin{array}{c}\text { CVC words } \\
\text { (e.g., PILOT) }\end{array}$ & $\begin{array}{c}\text { CV[C] words } \\
\text { (e.g., PILLOW) }\end{array}$ & $M$ \\
\hline Neutral primes & $453(1.5)$ & $442(1.4)$ & $452(1.0)$ & 449 \\
CV primes & $445(1.2)$ & $433(1.3)$ & $443(1.6)$ & 440 \\
CVC primes & $440(1.7)$ & $430(1.0)$ & $441(1.5)$ & 437 \\
\hline
\end{tabular}

Note. $\mathrm{CV}=$ consonant, vowel; $\mathrm{CVC}=$ consonant, vowel, consonant; $\mathrm{CV}[\mathrm{C}]=$ consonant, vowel, ambisyllabic consonant.

line with the segmental overlap hypothesis either. However, prime exposure duration was $20 \mathrm{~ms}$ shorter than in the Dutch experiments reported in Schiller (1998). This may be why the difference between the neutral control condition and the CV priming condition did not reach significance for all target structures. We come back to the issue of prime exposure duration in Experiment 5. At this point, additional experiments are needed to shed some more light on the nature of the priming effect.

\section{Experiment 3: \\ Word Naming With CV, CVC, and CV[C] Targets}

Experiment 3 was designed to test the same materials as in Experiment 2 using the word naming task. If the same overall pattern of results is obtained in this experiment as in the previous one, it would suggest that (a) the sublexical priming effect in English is not syllabic but segmental in nature and (b) this priming effect is independent of the presentation mode (pictorial or verbal) of the target.

\section{Method}

Participants. Eighteen participants from the same pool as described for Experiment 1 took part in Experiment 3.

Procedure. The procedure was the same as in Experiment 2 except that the targets were words. Words were presented in uppercase letters to minimize pure visual overlap between prime and target. Again, a nonproportional font was used (Courier). Target words were between four and six characters in length and subtended maximally $2.8^{\circ}$ of visual angle.

Materials. Primes and targets were the same as in Experiment 2 , but instead of line drawings, printed words were presented as cargets.

Design. The design was the same as in Experiment 2 except that there was no learning phase.

\section{Results}

Naming latencies shorter than $300 \mathrm{~ms}$ and longer than $1,000 \mathrm{~ms}$ were counted as outliers (less than $1 \%$ of the data). The mean naming latencies and error rates are summarized in Table 6. ANOVAs were run with target structure $(\mathrm{CV}$, CVC, or CV[C]), prime structure (CV, CVC, or neutral), and block $(1,2$, or 3$)$ as independent variables.

Error rates. There were $1 \%$ errors altogether. None of the main effects or interactions was significant.
Reaction times. The main effect of block was significant by items and marginally significant by participants, $F_{1}(2$, $34)=2.91, M S E=4,343.25, p=.068 ; F_{2}(2,90)=105.93$, $M S E=110.61, p<.001$. Targets were named faster in the third block ( $433 \mathrm{~ms}$ ) than in the second block ( $444 \mathrm{~ms}$ ) and in the first block (450 ms). Furthermore, block interacted with prime structure, $F_{1}(4,68)=3.53, M S E=98.83, p=$ $.011 ; F_{2}(4,180)=3.36, M S E=109.75, p=.011$. This interaction reflects the fact that the size of the priming effects differed among the blocks. As can be seen in Table 7, the difference between the neutral control and the CV priming condition is only $6 \mathrm{~ms}$ in Blocks 1 and 2 , whereas it is $13 \mathrm{~ms}$ in Block 3. The difference between the CV and the CVC priming condition is $2 \mathrm{~ms}$ in Blocks 1 and 3 , but $7 \mathrm{~ms}$ in Block 2. However, the three-way interaction between block, prime structure, and target structure did not approach significance, $F_{1}(8,136)=1.13$, ns; $F_{2}(8,180)=1.40$, ns, indicating that the pattern of the priming effects did not change with repeated production of the target words. Therefore, the data were collapsed across blocks and target categories for the subsequent analyses.

Most important, the main effect of prime structure was significant, $F_{1}(2,34)=81.45, M S E=8.36, p<.001 ; F_{2}(2$, 94) $=29.10, M S E=61.46, p<.001$. Target words were named fastest when preceded by a CVC prime $(437 \mathrm{~ms})$, slower when preceded by a CV prime $(440 \mathrm{~ms})$, and slowest when preceded by a neutral prime $(449 \mathrm{~ms})$. Dunnett's tests ( $p<.05$ ) showed that both the CV and the CVC priming condition differed significantly from the neutral control condition. Planned comparisons revealed that the 3-ms difference between the $\mathrm{CV}$ and the CVC priming condition was significant by participants and marginally significant by items, $t_{1}(17)=3.27, M S E=8.36, p<.05 ; t_{2}(47)=1.89$, $M S E=61.46, p<.10^{4}$

\section{Discussion}

The pattern of results is similar to the outcome of Experiments 1 and 2 in that there was no sign of a syllable priming effect. Both CV and CVC primes yielded significant

\footnotetext{
4 The fact that this 3-ms difference is significant by participants is due to the exceptionally low mean square error. However, it is clear that across experiments CVC primes are more effective than CV primes.
} 
Table 7

Mean Naming Latencies (in Milliseconds) Per Block and Prime Type in Experiment 3

\begin{tabular}{lcccc}
\hline \multirow{2}{*}{$\begin{array}{c}\text { Block and } \\
\text { prime structure }\end{array}$} & $\begin{array}{c}\text { TV words } \\
\text { (e.g., PILOT) }\end{array}$ & $\begin{array}{c}\text { CVC words } \\
\text { (e.g., PICNIC) }\end{array}$ & $\begin{array}{c}\text { CV[C] words } \\
\text { (e.g., PILLOW) }\end{array}$ & $M$ \\
\hline 1 Neutral primes & 460 & 448 & 457 & 455 \\
CV primes & 453 & 444 & 451 & 449 \\
CVC primes & 453 & 441 & 448 & 447 \\
2 Neutral primes & 450 & 443 & 457 & 450 \\
CV primes & 452 & 435 & 445 & 444 \\
CVC primes & 437 & 428 & 445 & 437 \\
3 Neutral primes & 448 & 437 & 442 & 442 \\
CV primes & 431 & 422 & 433 & 429 \\
CVC primes & 431 & 420 & 430 & 427 \\
\hline
\end{tabular}

Note. $\mathrm{CV}=$ consonant, vowel; $\mathrm{CVC}=$ consonant, vowel, consonant; $\mathrm{CV}[\mathrm{C}]=$ consonant, vowel, ambisyllabic consonant.

facilitatory effects for all three categories of target items as compared with a neutral control condition. Furthermore, CVC primes yielded stronger facilitation effects than CV primes showing that the size of the priming effect increased with an increase in segmental overlap between prime and target. However, the effect was only marginally significant by items. This is probably due to the fact that the overall effect size, that is, the difference between the neutral and the CVC priming condition, was relatively small in Experiment 3. In Experiment 5, we show that the magnitude of the effects can be increased-without changing the pattern-by extending the prime exposure duration.

One potential shortcoming of Experiments 2 and 3 may be that items of the individual target categories did not overlap in the initial letters. As a consequence, targets from different categories were not preceded by the same primes. Therefore, one might argue that the primes for CV, CVC, and CVIC] targets are not comparable. For example, it may be argued that certain primes have more possible pronunciations than others. For instance, if the CV primes for the $\mathrm{CV}$ targets were more ambiguous with regard to their pronunciations than the CV primes for the CVC targets, this could have diminished their relative priming efficiency on the CV targets and thus masked a syllable priming effect for those targets. Experiment 4 was designed to control for this potential disadvantage.

\section{Experiment 4: \\ Word Naming With CV and CVC Targets}

In Experiment 4 all target words had clear syllable boundaries. The effect of $\mathrm{CV}$ and $\mathrm{CVC}$ primes was tested on CV targets (e.g., se.cret) and CVC targets (e.g., sec.tion). The syllable priming hypothesis predicts an interaction between prime structure and target structure such that $\mathrm{CV}$ primes facilitate the naming of CV but not of CVC targets, and CVC primes yield facilitation of CVC but not of CV words. In contrast, the segmental overlap hypothesis predicts only a main effect of prime structure such that CVC primes facilitate the naming of the target words more than CV primes, independently of the target structure.

\section{Method}

Participants. Twenty-four participants from the same pool as described for Experiment 1 took part in Experiment 4.

Procedure. The procedure was the same as in Experiment 3 with the exception that masks and primes were seven characters in length. Target words were between four and seven characters in length and subtended maximally $3.2^{\circ}$ of visual angle.

Materials. Altogether, there were 48 bisyllabic words, $24 \mathrm{CV}$ words, and 24 CVC words (see Appendix C). In general, words were monomorphemic, except for three words (mileage, bondage, timer), which included some derivational morphology. In these cases, the syllable and morpheme boundaries did not coincide. The mean frequency of occurrence per one million word forms was $\mathbf{3 7 0}$ for the CV targets (e.g., secret) and 487 for the CVC targets (e.g., section) as determined by CELEX. Items from both target categories could be grouped into pairs such that the members of each pair shared the first three letters (e.g., sec).

There were two types of related primes, that is, CV primes (e.g., se) and CVC primes (e.g., sec). In addition, there was a neutral control prime.

Design. The design was the same as in Experiment 3.

\section{Results}

Naming latencies shorter than $300 \mathrm{~ms}$ and longer than $1,000 \mathrm{~ms}$ were counted as outliers (less than $1 \%$ of the data). One participant had to be excluded from the analyses because of technical problems. The mean naming latencies and error rates are summarized in Table 8. ANOVAs were run with target structure (CV or CVC), prime structure (CV, CVC, or neutral), and block $(1,2$, or 3$)$ as independent variables.

Error rates. There were $2 \%$ errors altogether. None of the main effects or interactions was significant.

Reaction times. The main effect of block was significant, $F_{1}(2,44)=36.75, M S E=103.02, p<.001 ; F_{2}(2$, $92)=219.39, M S E=93.85, p<.001$. Naming was faster in 
Table 8

Mean Naming Latencies (in Milliseconds) and Percentage of Errors (in Parentheses) in Experiment 4

\begin{tabular}{lccc}
\hline \multirow{2}{*}{$\begin{array}{c}\text { Prime } \\
\text { structure }\end{array}$} & \begin{tabular}{c}
$c$ \\
CV words \\
\cline { 2 - 3 } (e.g., RUMOR)
\end{tabular} & $\begin{array}{c}\text { CVC words } \\
\text { (e.g., RUMBLE) }\end{array}$ & $M$ \\
\hline Neutral primes & $475(1.8)$ & $469(1.3)$ & 472 \\
CV primes & $468(2.1)$ & $462(1.0)$ & 465 \\
CVC primes & $465(2.1)$ & $460(1.3)$ & 462 \\
\hline
\end{tabular}

Note. $\mathrm{CV}=$ consonant, vowel; $\mathrm{CVC}=$ consonant, vowel, consonant.

the third block ( $455 \mathrm{~ms}$ ) than in the second block ( $465 \mathrm{~ms}$ ) and the first block $(479 \mathrm{~ms})$. However, none of the interactions involving the variable block was significant. Therefore, the data were collapsed across target categories and blocks for the subsequent analyses.

The main effect of prime structure was again significant, $F_{1}(2,44)=36.74, M S E=17.02, p<.001 ; F_{2}(2,94)=$ $35.56, M S E=35.86, p<.001$. Targets were named faster when preceded by a CVC prime (462 ms) than when preceded by a $\mathrm{CV}$ prime (465 ms) and slowest when preceded by a neutral prime $(472 \mathrm{~ms})$. Dunnett's tests showed that both the CV and the CVC priming condition differed significantly $(p<.05)$ from the neutral control condition. Planned comparisons revealed that the 3-ms difference between the $\mathrm{CV}$ and the $\mathrm{CVC}$ priming condition was marginally significant, $t_{1}(22)=1.78, M S E=17.02$, $p<.10 ; t_{2}(47)=1.76, M S E=35.86, p<.10$.

\section{Discussion}

This experiment replicates the outcome of Experiment 3 with a different set of materials. The absence of an interaction between prime structure and target structure contradicts the syllable priming hypothesis. In contrast, the fact that the size of the facilitation effect increases when the overlap between prime and target is increased is in line with the segmental overlap hypothesis. Thus, the same pattern of results was found in three experiments so far.

However, the difference between the CV and the CVC priming condition was only marginally significant in Experiment 4. In Experiment 2, the difference between $\mathrm{CV}$ and CVC primes was significant, but the difference between the neutral control condition and the $\mathrm{CV}$ priming condition was significant for only the CVC targets. In Experiment 3, the difference between $\mathrm{CV}$ and CVC primes was significant by participants but only marginally significant by items. It is likely that this is a result of the small size of the priming effects in general. The CVC priming effect was $19 \mathrm{~ms}$ in Experiment 2,12 ms in Experiment 3, and only $10 \mathrm{~ms}$ in Experiment 4 . Compare this with the relatively large effects (in general larger than $30 \mathrm{~ms}$ ) obtained by Ferrand et al. (1997). At this point, we cannot offer an explanation for this difference in effect size. ${ }^{5}$ However, to show that the segmental overlap hypothesis also holds for English, we carried out a fifth experiment in which the prime exposure duration was extended.

\section{Experiment 5: \\ Word Naming With CV, CVC, and CVC Targets}

Experiment 5 is a replication of Experiment 3, the only difference being that primes are presented for $45 \mathrm{~ms}$ instead of $30 \mathrm{~ms}$. This should enable participants to extract more information from the primes on a larger proportion of trials such that the size of the priming effects may increase.

\section{Method}

Participants. Eighteen participants from the same pool as described for Experiment 1 took part in Experiment 5.

Procedure. The procedure was the same as in Experiment 3, except that the prime exposure duration was extended to $45 \mathrm{~ms}$.

Materials. The materials were the same as in Experiment 3.

Design. The design was the same as in Experiment 3.

\section{Results}

Naming latencies shorter than $300 \mathrm{~ms}$ and longer than $1,000 \mathrm{~ms}$ were counted as outliers (less than $1 \%$ of the data). The mean naming latencies and error rates are summarized in Table 9. ANOVAs were run with target structure (CV or CVC), prime structure (CV, CVC, or neutral), and block (1, 2 , or 3) as independent variables.

Error rates. There were $1 \%$ errors altogether. None of the main effects or interactions was significant.

Reaction times. The main effect of block was significant by items but not by participants, $F_{1}(2,34)<1 ; F_{2}(2,90)=$ $4.73, M S E=169.52, p=.011$. Block 3 was slightly faster $(436 \mathrm{~ms})$ than Block $2(439 \mathrm{~ms})$ and Block $1(440 \mathrm{~ms})$. Again, none of the interactions involving the variable block approached significance. Therefore, data were collapsed across blocks and target categories for the subsequent analyses.

Importantly, the main effect of prime structure was significant, $F_{1}(2,34)=50.99, M S E=35.54, p<.001$; $F_{2}(2,94)=67.05, M S E=68.63, p<.001$. Participants named target words fastest when they were preceded by a CVC prime ( $430 \mathrm{~ms})$, slower when they were preceded by a $\mathrm{CV}$ prime ( $436 \mathrm{~ms})$, and slowest when preceded by a neutral prime (449 ms). Dunnett's tests revealed that both the CV and the CVC priming condition differed significantly $(p<.05)$ from the neutral control condition. Planned comparisons showed that the 6-ms difference between the CV and the CVC priming condition was also significant, $t_{1}(17)=$

\footnotetext{
${ }^{5}$ However, the size of the priming effects obtained in the present study with a prime exposure duration of $30 \mathrm{~ms}$ resembles the effect size of the pilot experiments in Dutch (Schiller, 1998). In those experiments, the masked primes were presented for $33 \mathrm{~ms}$, resulting in an overall priming effect of $10 \mathrm{~ms}$. Similar effect sizes were obtained in the French experiments by Evinck (1997), who used a prime exposure duration of $29 \mathrm{~ms}$ (but failed to replicate Ferrand et al., 1996, in French). Boelhouwer's (1998) effects in Dutch are even smaller although he used a comparable prime exposure duration $(28 \mathrm{~ms})$. Compared with these studies, the effects obtained by Ferrand et al. (1997) are exceptionally large.
} 
Table 9

Mean Naming Latencies (in Milliseconds) and Percentage of Errors (in Parentheses) in Experiment 5

\begin{tabular}{lcccc}
\hline & \multicolumn{4}{c}{ Target structure } \\
\cline { 2 - 4 } $\begin{array}{c}\text { Prime } \\
\text { structure }\end{array}$ & $\begin{array}{c}\text { CV words } \\
\text { (e.g., PLOT) }\end{array}$ & $\begin{array}{c}\text { CVC words } \\
\text { (e.g., PICNIC) }\end{array}$ & $\begin{array}{c}\text { CV[C] words } \\
\text { (e.g., PILLOW) }\end{array}$ & $M$ \\
\hline Neutral primes & $452(0.7)$ & $444(1.0)$ & $451(1.4)$ & 449 \\
CV primes & $441(1.9)$ & $431(1.9)$ & $435(1.2)$ & 436 \\
CVC primes & $434(1.6)$ & $422(1.4)$ & $434(1.3)$ & 430 \\
\hline
\end{tabular}

Note. $\mathrm{CV}=$ consonant, vowel; $\mathrm{CVC}=$ consonant, vowel, consonant; $\mathrm{CV}[\mathrm{C}]=$ consonant, vowel, ambisyllabic consonant.

$2.91, M S E=35.54, p<.05 ; t_{2}(47)=3.29, M S E=68.63$, $p<.05$.

\section{Discussion}

The priming effects obtained in Experiment 5 contradict the syllable priming hypothesis but agree with the segmental overlap hypothesis. The differences between the individual priming conditions are significant, which is probably due to the fact that the CVC priming effect (19 ms) is almost twice as large as in the previous word naming experiments. However, it is still substantially smaller than the effects reported in the Ferrand et al. (1997) study.

Experiment 5 is important because it replicates the effect obtained in Experiment 3 . The only difference between these two experiments is the prime exposure duration and the identity of the participants. The analysis showed that the pattern of results is identical in the two experiments, but the size of the effect increased with an increase in prime exposure duration.

\section{General Discussion}

Five experiments were reported that investigated the effect of syllable priming in English speech production. Experiment 1A was a direct replication of Experiment 5 of Ferrand et al. (1997) but failed to replicate the syllable priming effect. Experiment 1B also failed to obtain a syllable priming effect, but an interesting-although differentpattern of results was found. Compared with the control condition, naming latencies for CV words were significantly shorter in the CVC but not in the CV priming condition, suggesting that segmental overlap and not syllabic overlap may be the crucial variable for the size of the priming effects. Experiment 2 further explored this issue with pictures as targets. Line drawings of common objects that were preceded either by a CV, a CVC, or a neutral prime were used in a naming task. According to the syllable priming hypothesis (Ferrand et al., 1996, 1997), an interaction between target structure and prime structure was expected such that $\mathrm{CV}$ targets would be named faster when preceded by CV primes than when preceded by CVC primes, whereas for CVC targets the situation would be reversed. However, no such interaction was found in this experiment. Instead, CVC primes again yielded significantly more priming than $\mathrm{CV}$ primes for all target categories, independent of their syllabic structures. This result is in line with the segmental overlap hypothesis (Schiller, 1998), according to which the size of the priming effect depends only on the amount of segmental overlap between prime and target. However, the CV primes in Experiment 2 did not yield significant priming for all target structures when compared with the neutral control condition. Therefore, more experiments were added in order to obtain additional empirical evidence for the segmental overlap hypothesis.

Experiment 3 replicated Experiment 2 with written words as target stimuli, and Experiment 4 used a different set of words. Experiments 3 and 4 yielded results that are in line with the segmental overlap hypothesis but contradict the syllable priming hypothesis. However, the overall size of the priming effects was relatively small in these two experiments and, although the CVC priming condition always yielded shorter naming latencies than the $\mathrm{CV}$ priming condition, the differences between these two priming conditions did not always reach significance. Therefore, in Experiment 5 the prime exposure duration was extended from $30 \mathrm{~ms}$ to $45 \mathrm{~ms}$. As a result, the overall priming effect was larger, which was probably due to the extended processing of the primes, and the results are fully in line with the segmental overlap hypothesis and the results obtained for Dutch (Schiller, 1998).

The present results are in contrast to the findings of Ferrand et al. $(1996,1997)$, who reported a syllable priming effect for French and English. Let us first discuss the French results reported in Ferrand et al. (1996). As opposed to Dutch and English, French has a simpler syllable structure with relatively clear syllable boundaries (but see Content, Kearns, \& Frauenfelder, 1998). If it is assumed that segments in French are marked for syllable position in the input, as suggested by comprehension studies that found syllabic effects in speech segmentation (e.g., Mehler, Dommergues, Frauenfelder, \& Segui, 1981; Pallier, Sebastían-Galles, Felguera, Christophe, \& Mehler, 1993), the syllable priming effect in French can be accounted for by Levelt's speech production model. One of the basic assumptions of this model is that active phonological segments in the perceptual network can directly affect the corresponding segment nodes in the production lexicon (Levelt et al., 1999, p. 7). It is proposed here that the segments of the visually masked primes in French contain information about their syllable positions. That is, upon presentation of the prime bal, for 
instance, segments specified for syllable position are activated in the perceptual network, for example, $\left(b_{\text {onset }}, a_{\text {mucleus, }}\right.$, $\left.l_{\text {coda }}\right)_{\sigma}$. This information activates the corresponding segment nodes at the phonological output level. In case this perceptual information is in line with the syllable positions computed for the production of a target word form, for example, bal.con, a syllable priming effect results. The word form balade is not primed by bal because there is a positional mismatch: The $\pi /$ in bal is specified for coda position, whereas the $N /$ in ba.lade is specified for onset position; that is, bal primes a syllable that is different from the first syllable of ba.lade. In case of the prime $b a$ ( $b_{\text {onset }}$ $\left.a_{\text {nucleus }}\right)_{\sigma}$ and the target ba.lade, there is again a segmental and a syllabic match resulting in a syllable priming effect, whereas $b a$ does not prime the first syllable of the target bal.con.

Now let us turn to the contrasting findings for English reported in Ferrand et al. (1997) and in the present study. This discrepancy cannot be due to differences in prime processing time because the prime exposure duration used in the first four experiments of this study $(30 \mathrm{~ms})$ was practically the same as in the Ferrand et al. study $(29 \mathrm{~ms})$. Moreover, prime exposure duration does not seem to influence the quality of the effect: When the prime was presented longer in Experiment $5(45 \mathrm{~ms})$, only the magnitude of the segmental overlap effect was increased as compared with Experiment 3, but the pattern of the effect remained the same.

There are several reasons why the results that were found in this study in support of the segmental overlap effect are more convincing than the data provided by Ferrand et al. (1997) to support the syllable priming effect. First of all, four of the five experiments reported by Ferrand et al. are compatible with the segmental overlap hypothesis: In Experiment 1, CVC targets such as helmet were named faster when preceded by CVC primes than when preceded by $\mathrm{CV}$ primes. The first experiment also included CV[C] targets, which cannot tell us anything about the syllable priming hypothesis because the syllable boundaries in these words are ambiguous. The second experiment was a lexicaldecision experiment and cannot speak to the role of the syllable in speech production. Experiment 3 tested CVC targets alone and yielded the same result as Experiment 1, and the fourth experiment tested only ambisyllabic CV[C] targets, which cannot speak to the syllable priming hypothesis. It is only Experiment 5 that clearly supported the syllable priming hypothesis and contradicted the segmental overlap hypothesis. In this experiment, CV targets were named faster in the CV than in the CVC priming condition, although CVC primes had a larger overlap with the targets than did CV primes. However, this experiment has a rather small empirical basis because only 24 data points were obtained maximally from each participant. In contrast, five experiments of the present study showed a main effect of prime structure such that CVC primes yielded more priming than $\mathrm{CV}$ primes independent of the syllabic structure of the target. This effect clearly contradicts the syllable priming hypothesis. In addition, the individual differences between the priming conditions were not always significant, but the pattern of the effects was the same in all experiments. Furthermore, similar results were found using different tasks (picture and word naming), different sets of materials, and different prime exposure durations ( 30 and $45 \mathrm{~ms}$ ). Finally, the results of each experiment of the present study are based on much more empirical data than Experiment 5 of the Ferrand et al, study.

Second, in contrast to the Ferrand et al. (1997) study, the present study included a picture naming task. This is important for two reasons. First, it is well known that words can be named on the basis of nonlexical GPC rules (Bajo, 1988; Coltheart, 1978; Coltheart, Curtis, Atkins, \& Haller, 1993), whereas picture naming presumably involves accessing the whole-word representation of the target in the mental lexicon. To access the picture name, the concept must be activated first in order to retrieve semantic and word form information (e.g., Caramazza, 1996; Dell \& O'Seaghdha, 1992; Glaser, 1992; Huttenlocher \& Kubicek, 1983; Levelt, 1989). Second, although the prime and the target are presented in different cases, pure visual overlap between prime and target-in addition to graphemic overlap-is still possible in word naming as, for instance, in cov-COVERT (Davis \& Forster, 1994). No such visual overlap is possible when prime and target are presented in different modalities. Because we obtained similar effects in picture and word naming (Experiments 2 and 3), the modality of target presentation does not seem to be crucial for the type of priming effect (e.g., segmental vs. syllabic).

In the previous section, we argued that the data put forward by Ferrand et al. (1997) in support of the syllable priming hypothesis are not compelling and that the present data should be given more credence. In the next section, we try to give a theoretical account for our data in terms of Levelt's model emphasizing the role of individual segments and the segmental overlap between prime and target. According to our view, the visually masked letter prime activates orthographic segments from left to right, which subsequently send activation to phonological segments (for further evidence of left-to-right sequentiality in GPC, see Coltheart, Woollams, Kinoshita, \& Perry, 1999; Rastle \& Coltheart, 1999). Take the target pilot, for instance, and its two primes $p i$ and pil. The primes enter the speech production system by way of the subword level orthography-tophonology (see Figure 1). ${ }^{6}$ Ferrand and Grainger (1994) estimated the time lag between the influence of orthographic and phonological information in visual word recognition to be approximately $30 \mathrm{~ms}$ (see also Perfetti \& Bell, 1991). When the target is to be phonologically encoded, some of its phonological segments are already preactivated by the prime. The number of segments that are preactivated depends on the number of letters in the prime. The larger the number of letters in the prime (overlapping with the beginning of the target), the more segments receive preactivation, and therefore the target will be named faster. That is

\footnotetext{
${ }^{6}$ The arrow from subword level orthography-to-phonology to metrical spellout is dotted because it is not clear whether there is an impact of the subword level orthography on the computation of a metrical structure for nonwords (Rastle \& Coltheart, in press).
} 
why pil will facilitate the naming of pilot more than pi. This segmental activation account is supported by the onset effect found by Forster and Davis (1991). These authors found a facilitatory effect in word naming for high-density words when prime and target shared the initial segment. However, the effect was also obtained with nonwords, suggesting that the onset effect is nonlexical in nature. In Levelt's model of phonological encoding the preactivation of segments presumably occurs before the process of segmental spellout. After segment-to-frame association, syllables are created and the segments have already received a specific position in the syllable. Therefore, if the priming effect occurs later, one would expect additional priming when the prime matches the first syllable of the target.

However, there is one problem with this account. The problem is related to the spelling-to-sound inconsistency of the English language (Jared, 1997; Jared \& Seidenberg, 1990; Treiman, Mullennix, Bijeljac-Babic, \& RichmondWelty, 1995). How are both the primes pi and pil able to yield priming for the targets pilot /parlat/ and pillow $/ \mathrm{pI}[1] v a / ?^{7}$ When pronounced in isolation, $p i$ is either realized as $/ \mathrm{pi} / / \mathrm{paI} /$, or $/ \mathrm{p} 2 /$, whereas pil has only one pronunciation, namely $/ \mathrm{pl} / .^{8}$ One may speculate that in order to be effective primes for pilot and pillow, the orthographic units pi or pil activate a whole set of possible corresponding phonological units. For instance, the grapheme (i) may be connected to the phonemes $/ \mathrm{i} /, / \mathrm{ar} /, / \mathrm{l} /$, and $/ \mathrm{I}$. Whenever $(\mathrm{i}\rangle$ appears in a prime, all its possible pronunciations become preactivated. The amount of activation may be weighted by the frequency with which a grapheme is pronounced as a particular phoneme (Berndt, Reggia, \& Mitchum, 1987). This account would also capture the Dutch data: In Dutch, the vowel graphemes $\langle a$ ), (o), (e), and (i) each have two possible phonological realizations that differ in quantity and quality depending on the syllable type. A vowel that occurs in an open syllable (e.g., ba.lie 'counter') is pronounced long (i.e., /a), whereas a vowel that occurs in a closed syllable (e.g., bal.sem 'balsam') has a short pronunciation (i.e., $/ \mathrm{\alpha} /$ ). Thus, the $\mathrm{CV}$ prime $b a$ would naturally be pronounced $/ \mathrm{ba} /$ and would therefore match the pronunciation of the CV target balie, whereas the CVC prime bal would be pronounced /bal/ and match the pronunciation of the CVC target balsem. Therefore; syllabic priming effects would be expected on the basis of matches in pronunciation between prime and target. However, this was not the case: CVC primes yielded priming for both balie and balsem, and so did CV primes but to a lesser extent, supporting the segmental overlap hypothesis (Schiller, 1998). Under the assumption that vowel graphemes are connected to a set of vowel segments with different vowel lengths and vowel qualities at the phonological encoding level (e.g., $(a)-/ a /$ and (a) $-/ a)$, the segmental priming effect in Dutch becomes conceivable.

The idea that a specific grapheme activates several phonemes has been suggested before in the literature on certain types of surface dyslexic reading (see Shallice \& McCarthy, 1985, for an overview). Some patients seem to transfer information about letter names directly from visual letter forms to the phonological system. Patient ROG (Shallice \& Warrington, 1980), for instance, could give the characteristic sound of an individual letter (e.g., $u \rightarrow \Lambda$ ) but not its name. Shallice and McCarthy (1985) called these dyslexic patients "letter-sound by letter-sound readers" (p. 367).

\section{Altemative Interpretations of the Effects Obtained in the Present Study}

There are, however, some alternative accounts that may explain the segmental overlap effect. The first one concerns syllable frequency. There are some reports in the literature claiming that syllable frequency plays a role in lexicaldecision and naming tasks. Carreiras, Álvarez, and de Vega (1993) found inhibitory syllable frequency effects both in lexical-decision and naming tasks in Spanish. Words containing high-frequency syllables were harder to recognize and to name than words consisting of low-frequency syllables (see also Domínguez, de Vega, \& Cuetos, 1997). Recently, however, Perea and Carreiras (1998), also studying Spanish, reported inhibitory effects of syllable frequency in visual word recognition but facilitatory effects in word naming. Is it possible that these facts about syllable frequency can account for the pattern of results in the present study? Word frequency effects are located at the word form level (Jescheniak \& Levelt, 1994; Levelt, Praamstra, Meyer, Helenius, \&

\footnotetext{
${ }^{7}$ Because similar priming effects were found in word and picture naming, the effect cannot solely be due to orthographic overlap. The experiments in this study suffered from the same mapping problem as the experiments of the Ferrand et al. (1997) study and yet different results were obtained. It may be the case that the priming effects in this study are mainly due to some specific items in which the GPC mapping is fairly consistent, whereas in cases in which this mapping is highly irregular the priming is clearly diminished. However, a look at the individual item means of Experiment 5 did not reveal any systematic effects. Take, for instance, the targets baby and baker: Compared with the neutral condition, the CV prime ba yielded 23-ms facilitation for baby, but 3-ms inhibition for baker. Furthermore, cases in which the same CV prime matches the pronunciation of the target (e.g. pi-pilot; priming effect: $6 \mathrm{~ms}$ ) did not generally yield more priming than cases in which it mismatches (e.g., pi-pillow; priming effect: $8 \mathrm{~ms}$ ).

${ }^{8}$ In a pronunciation experiment, we empirically tested the assumption that $\mathrm{CV}$ and CVC would be pronounced differently in isolation. This assumption is based on the phonological characteristics of the English language: English does not allow for short vowels to occur in open syllables (except for schwa, which behaves like a long vowel in this respect). Eighteen native speakers of English saw the CV and CVC primes that were used in the present study one at a time on a computer screen and were asked to pronounce each prime as if it was an English word (for a similar method see Ryan, Ostergaard, \& Norton, 1999). Responses were scored by a trained phonetician. The results of this test showed that the vowel in CV primes received a long pronunciacion in $97 \%$ of the cases, whereas it was pronounced as a short vowel in only $3 \%$ of the cases. CVC primes, however, received a short pronunciation in almost all cases $(97 \%)$ and a long pronunciation in only $3 \%$ of the cases.
} 
Salmelin, 1998). The higher the frequency of a word form, the shorter the naming latencies. Levelt and Wheeldon (1994) reported a similar effect also for syllable frequency independent of word frequency. If the facilitatory syllable frequency effect in naming reported by Perea and Carreiras (1998) for Spanish also holds for English-an assumption for which there is no independent evidence-it may be the case that the CVC primes in the present study had a higher frequency than the $\mathrm{CV}$ primes. Therefore, upon recognition, they may have been able to send activation to the corresponding segments faster than the $\mathrm{CV}$ primes. This might account for the general advantage of the CVC primes compared with the CV primes in this study and explain the segmental overlap effect.

However, a careful investigation of the (orthographic) syllable frequencies does not support this view. As can be seen in Table 10, CVC primes always had lower frequencies than CV primes. Usually, the syllable frequency of the CV primes was between 3 and 5 times higher than the syllable frequency for the CVC primes. In Experiments 1A and 1B, which contained the same materials as the crucial Experiment 5 of the Ferrand et al. (1997) study, the syllable frequency of the $\mathrm{CV}$ primes was in fact 33 times higher than for CVC primes. This shows that syllable frequency cannot account for the pattern of results found in this study.

Second, it could be argued that the difference in results (syllable vs. segmental overlap effect) is due to the difference in naming latencies and correlated differences in response preparation between the Ferrand et al. (1997) study and the present study (L. Ferrand, personal communication, September 1998; for a related phenomenon in speech perception see Sebástian-Gallés, Dupoux, Segui, \& Mehler, 1992). Shorter naming latencies may make it less likely to get the syllabic effects. Indeed, participants in this study were approximately $100 \mathrm{~ms}$ faster across the four word naming experiments than in the Ferrand et al. study. However, the frequencies of the stimuli used in the two studies are comparable (except for Experiment 4 of the present study). Furthermore, even when participants did not receive any practice blocks and as a result produced longer naming latencies in word and picture naming (Schiller, 1999), the segmental overlap effect does not turn into a syllable priming effect. Instead, clear segmental overlap effects were obtained even when participants were less trained and produced the targets less often.

Finally, one could claim that the segmental overlap effect does not arise at a sublexical level-as argued here--but rather at a lexical level. Although this point does not affect the principal goal of this article, which was to determine whether or not there is a syllable priming effect in English, this study does not provide a means to distinguish between these two possibilities. According to the lexical account, primes may actually preactivate (cohorts of words in the lexicon that have the same initial segments instead of preactivating only their segments. Calculations of the cohort sizes (i.e., number of words beginning with the same letters) are on average 11.76 times bigger for the $C V$ primes than for the CVC primes. Therefore, the set of words being activated by the CV primes is bigger than the set of words receiving activation from the CVC primes, and thus the probability of selecting a particular target from a cohort of preactivated words is supposedly higher in the CVC priming condition than in the CV priming condition. Therefore, the fact that the CVC primes always yielded the largest priming effects would also be compatible with a lexical account. However, considering the sublexical priming effect found with nonword targets in French (Ferrand et al., 1996, Experiment 2) and the onset effect in English (Forster \& Davis, 1991), it seems unlikely that the priming effects reported in this article are only due to lexical activation. Rather, they must (at least in part) be due to segmental activation in the phonological lexicon.

\section{Conclusion}

The present study provides data that clearly contradict the syllable priming effect reported by Ferrand et al. (1997) but are consistent with the segmental overlap hypothesis proposed by Schiller (1998). However, the present study does not allow us to decide whether or not syllables play a functional role in speech production. Presumably, the masked priming paradigm is not tapping into the right processing level to pick up effects of late syllabification predicted by Levelt's model or to detect syllabic effects at the lexical level predicted by Dell's model. However, our results clearly demonstrated that Ferrand et al.'s study should not be taken as evidence for the claim that the syllable plays a functional role in English speech production. Instead, the present study showed consistently that the amount of segmental overlap between a prime and a target is crucial.

Table 10

Orthographic Syllable Frequencies Per One Million Syllables (Computed From CELEX) for $C V$ and $C V C$ Primes

\begin{tabular}{lrr}
\hline \multicolumn{1}{c}{ Study } & \multicolumn{2}{c}{ Type of prime } \\
\cline { 2 - 3 } & CV & CVC \\
\hline Ferrand et al. (1997), Experiments 1-4 & 2,097 & 430 \\
Present study, Experiments 1A, 1B (see Ferrand et al., 1997, Experiment 5) & 4,722 & 143 \\
Present study, Experiments 2, 3, and 5 & 1,417 & 298 \\
Present study, Experiment 4 & 752 & 226 \\
\hline Note. CV = consonant, vowel; CVC = consonant vowel, consonant. & &
\end{tabular}

Note. $\mathrm{CV}=$ consonant, vowel; $\mathrm{CVC}=$ consonant, vowel, consonant. 


\section{References}

Baayen, R. H., Piepenbrock, R., \& Gulikers, L. (1995). The CELEX lexical database [CD-ROM]. Philadelphia, PA: Linguistic Data Consortium, University of Pennsylvania.

Bajo, M.-T. (1988). Semantic facilitation with pictures and words. Joumal of Experimental Psychology: Learning, Memory, and Cognition, 14, 579-589.

Berndt, R. S., Reggia, J. A., \& Mitchum, C. C. (1987). Empirically derived probabilities for grapheme-to-phoneme correspondences in English. Behavior Research Methods, Instruments, \& Computers, 19, 1-9.

Boelhouwer, B. (1998). From letter strings to phonemes: The role of orthographic context in phonological recoding. Unpublished doctoral dissertation, Nijmegen University, Nijmegen, the Netherlands.

Brown, C. M., \& Hagoort, P. (1993). The processing nature of the N400: Evidence from masked priming. Journal of Cognitive Neuroscience, 5, 34-44.

Burnage, G. (1990). CELEX: A guide for users. Nijmegen, the Netherlands: Centre for Lexical Information.

Caramazza, A. (1996, April). The brain's dictionary. Nature, 380, 485-486.

Carreiras, M., Álvarez, C. J., \& de Vega, M. (1993). Syllable frequency and visual word recognition in Spanish. Journal of Memory and Language, 32, 766-780.

Coltheart, M. (1978). Lexical access in simple reading tasks. In G. Underwood (Ed.), Strategies of information processing (pp. 151-216). London: Academic Press.

Coltheart, M., Curtis, B., Atkins, P., \& Haller, M. (1993). Models of reading aloud: Dual-route and parallel-distributed-processing approaches. Psychological Review, 100, 589-608.

Coltheart, M., Woollams, A., Kinoshita, S., \& Perry, C. (1999). A position-sensitive Stroop effect: Further evidence for a left-toright component print-to-speech conversion. Psychonomic Bulletin \& Review, 6, 456-463.

Content, A., Kearns, R., \& Frauenfelder, U. (1998). Boundaries versus onsets in syllabic segmentation. Manuscript submitted for publication.

Costa, A., \& Sebastián-Gallés, N. (1998). Abstract phonological structure in language production: Evidence from Spanish. Journal of Experimental Psychology: Learning, Memory, and Cognition, 24, 886-903.

Davis, C., \& Forster, K. I. (1994). Masked orthographic priming: The effect of prime-target legibility. The Quarterly Joumal of Experimental Psychology, 47A, 673-697.

Dell, G. S. (1986). A spreading-activation theory of retrieval in sentence production. Psychological Review, 93, 283-321.

Dell, G. S. (1988). The retrieval of phonological forms in production: Tests of predictions from a connectionist model. Joumal of Memory and Language, 27, 124-142.

Dell, G. S., \& O'Seaghdha, P. G. (1992). Stages of lexical access in language production. Cognition, 42, 287-314.

Domínguez, A., de Vega, M., \& Cuetos, F. (1997). Lexical inhibition from syllabic units in Spanish visual word recognition. Language and Cognitive Processes, 12, 401-422.

Evinck, S. (1997). Production de la parole en français: Investigation des unités impliquées dans l'encodage phonologique des mots [Speech production in French: Investigation of the units implied during the phonological encoding of words]. Unpublished doctoral dissertation, Bruxelles University, Brussels, Belgium.

Ferrand, L., \& Grainger, J. (1994). Effects of orthography are independent of phonology in masked form priming. The Quarterly Journal of Experimental Psychology, 47A, 365-382.
Ferrand, L., \& Segui, J. (1998). The syllable's role in speech production: Are syllables chunks, schemas, or both? Psychonomic Bulletin \& Review, 5, 253-258.

Ferrand, L., Segui, J., \& Grainger, J. (1996). Masked priming of word and picture naming: The role of syllabic units. Journal of Memory and Language, 35, 708-723.

Ferrand, L., Segui, J., \& Humphreys, G. W. (1997). The syllable's role in word naming. Memory \& Cognition, 35, 458-470.

Forster, K. I., \& Davis, C. (1991). The density constraint on form-priming in the naming task: Interference effects from a masked prime. Journal of Memory and Language, 30, 1-25.

Francis, W. N., \& Kučra, H. (1982). Frequency analysis of English usage: Lexicon and grammar. Boston: Houghton Mifflin.

Fromkin, V. A. (1971). The non-anomalous nature of anomalous utterances. Language, 47, 27-52.

Glaser, W. R. (1992). Picture naming. Cognition, 42, 61-105.

Gum, T., \& Bub, D. (1988). Psychlab manual. Montreal, Quebec, Canada: McGill University.

Huttenlocher, J., \& Kubicek, L. F. (1983). The source of relatedness effects on naming latency. Journal of Experimental Psychology: Learning, Memory, and Cognition, 9, 486-496.

Jared, D. (1997). Spelling-sound consistency affects the naming of high-frequency words. Journal of Memory and Language, 36, 505-529.

Jared, D., \& Seidenberg, M. S. (1990). Naming multisyllabic words. Journal of Experimental Psychology: Human Perception and Performance, 16, 92-105.

Jescheniak, J. D., \& Levelt, W. J. M. (1994). Word frequency effects in speech production: Retrieval of syntactic information and of phonological form. Journal of Experimental Psychology: Learning, Memory, and Cognition, 20, 824-843.

Levelt, W. J. M. (1989). Speaking: From intention to articulation. Cambridge, MA: MIT Press.

Levelt, W. J. M. (1992). Accessing words in speech production: Stages, processes and representations. Cognition, 42, 1-22.

Levelt, W. J. M. (1993). Timing in speech production with special reference to word form encoding. Annals of the New York Academy of Sciences, 682, 283-295.

Levelt, W. J. M. (1998). The genetic perspective in psycholinguistics or where do spoken words come from? Journal of Psycholinguistic Research, 27, 167-180.

Levelt, W. J. M., Praamstra, P., Meyer, A. S., Helenius, P., \& Salmelin, R. (1998). A MEG study of picture naming. Joumal of Cognitive Neuroscience, 10, 553-567.

Levelt, W. J. M., Roelofs, A., \& Meyer, A. S. (1999). A theory of lexical access in speech production. Behavioral and Brain Sciences, 22, 1-75.

Levelt, W. J. M., \& Schiller, N. O. (1998). Is the syllable frame stored? Behavioral and Brain Sciences, $21,520$.

Levelt, W. J. M., \& Wheeldon, L. (1994). Do speakers have access to a mental syllabary? Cognition, 50, 239-269.

Mehler, J., Dommergues, J. Y., Frauenfelder, U., \& Segui, J. (1981). The syllable's role in speech segmentation. Jourmal of Verbal Learning and Verbal Behavior, 20, 298-305.

Meijer, P. J. A. (1994). Phonological encoding: The role of suprasegmental structures. Unpublished doctoral dissertation, Nijmegen University, Nijmegen, the Netherlands.

Meijer, P. J. A. (1996). Suprasegmental structures in phonological encoding: The CV structure. Journal of Memory and Language, $35,840-853$.

Meyer, A. S. (1992). Investigation of phonological encoding through speech error analyses: Achievements, limitations, and alternatives. Cognition, 42, 181-211.

Pallier, C., Sebastían-Galles, N., Felguera, T., Christophe, A., \& Mehler, J. (1993). Attentional allocation within the syllabic 
structure of spoken words. Journal of Memory and Language, 32, 373-389.

Perea, M., \& Carreiras, M. (1998). Effects of syllable frequency and syllable neighborhood frequency in visual word recognition. Journal of Experimental Psychology: Human Perception and Performance, 24, 134-144.

Perfetti, C. A., \& Bell, L. (1991). Phonemic activation during the first $40 \mathrm{~ms}$ of word identification: Evidence from backward masking and priming. Journal of Memory and Language, 30 , 473-485.

Rastle, K., \& Coltheart, M. (1999). Serial and strategic effects in reading aloud. Journal of Experimental Psychology: Human Perception and Performance, 25, 482-503.

Rastle, K. \& Coltheart, M. (in press). Lexical and nonlexical print-to-sound translation of disyllabic words and nonwords. Journal of Memory and Language.

Roelofs, A. (1997a). Syllabification in speech production: Evaluation of WEAVER. Language and Cognitive Processes, 12, $657-693$.

Roelofs, A. (1997b). The WEAVER model of word-form encoding in speech production. Cognition, 64, 249-284.

Roelofs, A., \& Meyer, A. S. (1998). Metrical structure in planning the production of spoken words. Journal of Experimental Psychology: Learning, Memory, and Cognition, 24, 922-939.

Ryan, L., Ostergaard, A., \& Norton, L. (1999). Search and selection processes in word stem completion performance and the decline in implicit and explicit performance across the lifespan. Manuscript submitted for publication. University of Arizona.

Schiller, N. O. (1998). The effect of visually masked syllable primes on the naming latencies of words and pictures. Journal of Memory and Language, 39, 484-507.

Schiller, N. O. (1999). Masked syllable priming of English nouns. Brain and Language, 68, 300-305.

Schiller, N. O., Meyer, A. S., Baayen, R. H., \& Levelt, W. J. M. (1996). A comparison of lexeme and speech syllables in Dutch. Journal of Quantitative Linguistics, 3, 8-28.
Schiller, N. O., Meyer, A. S., \& Levelt, W. J. M. (1997). The syllabic structure of spoken words: Evidence from the syllabification of intervocalic consonants. Language and Speech, 40 , $103-140$

Sebastián-Gallés, N., Dupoux, E., Segui, J., \& Mehler, J. (1992). Contrasting syllabic effects in Catalan and Spanish. Journal of Memory and Language, 31, 18-32.

Sevald, C. A., Dell, G. S., \& Cole, J. S. (1995). Syllable structure in speech production: Are syllables chunks or schemas? Journal of Memory and Language, 34, 807-820.

Shallice, T., \& McCarthy, R. (1985). Phonological reading: From patterns of impairment to possible procedures. In K. E. Patterson, J. C. Marshall, \& M. Coltheart (Eds.), Surface dyslexia: Neuropsychological and cognitive studies of phonological reading (pp. 361-397). Hillsdale, NJ: Erlbaum.

Shallice, T., \& Warrington, E. K. (1980). Single and multiple component central dyslexic syndromes. In M. Coltheart, $\mathrm{K}$. E Patterson, \& J. C. Marshall (Eds.), Deep dyslexia (pp. 119-145). London: Routledge \& Kegan Paul.

Shattuck-Hufnagel, S. (1987). The role of word onset consonants in speech production planning: New evidence from speech error patterns. In E. Keller \& M. Gopnik (Eds.), Motor and sensory processing in language (pp. 17-51). Hillsdale, NJ: Erlbaum.

Shattuck-Hufnagel, S. (1992). The role of word structure in segmental ordering. Cognition, 42, 213-259.

Treiman, R. (1983). The structure of spoken syllables: Evidence from novel word games. Cognition, 15, 49-74.

Treiman, R. (1984). On the status of final consonant clusters in English syllables. Journal of Verbal Leaming and Verbal Behavior, 23, 343-356.

Treiman, R., \& Danis, C. (1988). Syllabification of intervocalic consonants. Journal of Memory and Language, 27, 87-104.

Treiman, R., Mullennix, J., Bijeljac-Babic, R., \& Richmond-Welty, E. D. (1995). The special role of rimes in the description, use, and acquisition of English orthography. Journal of Experimental Psychology: General, 124, 107-136. 
Appendix A

Stimulus Materials in Experiments 1A and 1B

\begin{tabular}{lll}
\hline \multicolumn{3}{c}{ Target structure } \\
\hline & \multicolumn{1}{c}{ CV targets } & \\
\hline demote & recital \\
reversal & divorce \\
covert & report \\
vanilla & reveal \\
relaxing & depend \\
dilemma & demand \\
tomato & remorse \\
November & remain \\
device & retirement \\
sarong & carouse \\
delicious & select \\
remember & relate \\
\hline
\end{tabular}

Note. $\mathrm{CV}=$ consonant, vowel.

\section{Appendix B}

Stimulus Materials in Experiments 2, 3, and 5

\begin{tabular}{lll}
\hline & \multicolumn{2}{c}{ Target structure } \\
\hline CV targets & CVC targets & CV[C] targets \\
\hline baby & monkey & mirror \\
tiger & doctor & pillow \\
tuba & jester & carrot \\
moped & magnet & saddle \\
cable & picnic & parrot \\
silo & banjo & barrel \\
baker & pencil & funnel \\
bison & basket & bullet \\
pilot & pelvis & collar \\
ruler & donkey & hammer \\
raven & window & cannon \\
totem & helmet & beggar \\
razor & sandal & button \\
robot & cactus & ladder \\
zebra & candle & coffin \\
table & napkin & mummy \\
\hline
\end{tabular}

Note. $\mathrm{CV}=$ consonant, vowel; $\mathrm{CVC}=$ consonant, vowel, consonant; CV[C] = consonant, vowel, ambisyllabic consonant.
Appendix C

Stimulus Materials in Experiment 4

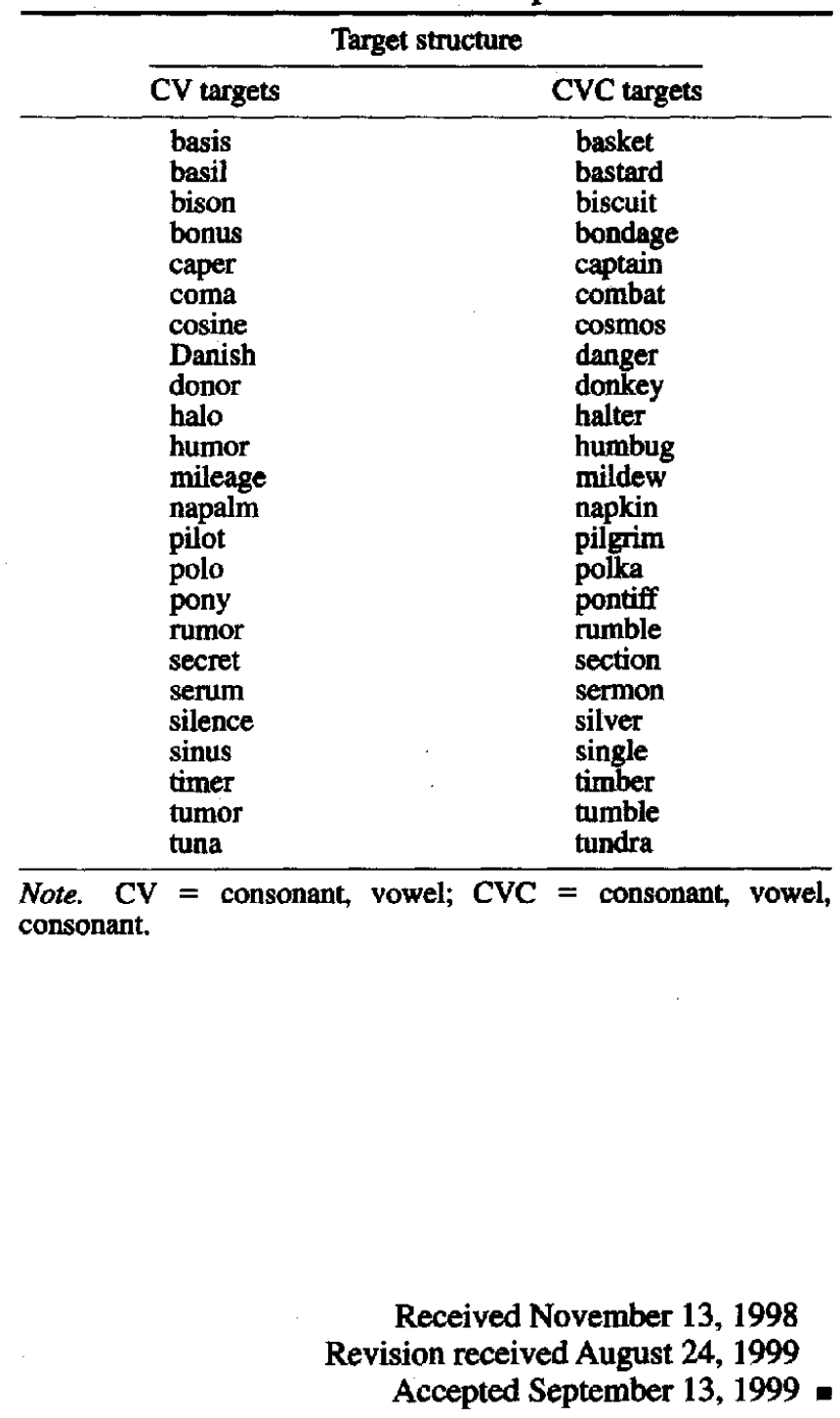

